\title{
ANALISIS POTENSI LIMBAH TULANG AYAM DAN IKAN DARI PKL SEBAGAI SUMBER MINERAL KALSIUM FOSFAT
}

\author{
Ahmad Kafrawi Nasution, Ekie Gilang Permata \\ Program Studi Teknik Mesin, FT - Universitas Muhammadiyah Riau \\ Jurusan Teknik Industri, FST - Universitas Islam Negeri Sultan Syarif Kasim Riau \\ ahmadkafrawi@umri.ac.id,ekiegp@yahoo.com,
}

\begin{abstract}
This study aimed to find out how much potential waste from chicken bones and fish collected from street vendors in the city of Pekanbaru to pulverized bone and mineral calcium phosphate nanoparticle size. This research is motivated by many vendors who are considered disturbing the aesthetics and cleanliness of the city. The research was conducted in the city of Pekanbaru by using primary data obtained from a survey of street vendors. While secondary data obtained from the Office of Market town of Pekanbaru, statistical data and the results of previous studies. Data samples are taken randomly from street vendors in the city of Pekanbaru based on the types of food sold as roasted chicken and fried catfish. The process of making bone powder are derived from chicken and fish bones through several stages. For bone drying process is done at a temperature of $100^{\circ} \mathrm{C}$ for 15 minutes. As for the bone turnover process is performed at a temperature of $700{ }^{\circ} \mathrm{C}$ for 6 hours. The results showed that the huge potential of the waste bones if used as a source of mineral raw materials Calcium Phosphate. This research could also describe an increase in economic value if it produces powder bone and bone powder with the size of the nanoparticles.
\end{abstract}

Keywords: waste, chicken and fish bones, calcination, hydroxyapatite nanoparticles.

\section{PENDAHULUAN}

Kalsium fosfat berupa hydroxyapatite (HAp) dan tricalcium phosphate (TCP) merupakan mineral yang dapat dijadikan biomaterial seperti biokeramik dan bioaktif. Biomaterial ini menjadi kandidat yang baik (good candidates) untuk aplikasi orthopaedic, dental and maxillofacial (de Groot 1980, Rivera, Araiza et al. 1999, Saiz, Gremillard et al. 2007, Gergely, Wéber et al. 2010, Nikpour, Rabiee et al. 2012). Jika dilihat komposisi kimianya maka mineral ini merupakan komponen utama dari inorganik tulang (Nurlaela, Dewi et al. 2014). Sedangkan mineral tulang dari makluk hidup disebut sebagai apatit biologi (Nurlaela, Dewi et al. 2014). Apatit dalam jaringan makhluk hidup banyak mengandung Karbonat (Nurlaela, Dewi et al. 2014). Ion Karbonat dapat menggantikan gugus Posfat atau Hidroksil (Nurlaela, Dewi et al. 2014) pada hydroxyapatite (HAp) (Darmayanto 2009). HAp dan TCP dapat diproduksi dari karang (coral) (Ripamonti, Crooks et al. 2009), kerang (seashell) (Vecchio, Zhang et al. 2007), cangkang telur (eggshell) (Rivera, Araiza et al. 1999, Lee and Oh 2003, Balázsi, Wéber et al. 2007, Gergely, Wéber et al. 2010), tulang sapi (bovine bones) (Jang and Kang 2002) dan tulang ikan (fish bones) (Ozawa and Suzuki 2002) dengan mengontrol perbandingan rasio Kalsium dan Posfor $(\mathrm{Ca} / \mathrm{P})$
(Balázsi, Kövér et al. 2007). Sejumlah cara telah dikembangkan untuk memproduksi serbuk HAp dan TCP, seperti metode mechanochemical, solgel, chemical precipitation, hydrothermal dan microemulsion (Wu, Tsou et al. 2013).

Limbah tulang ayam dan ikan dari PKL khususnya di Kota Pekanbaru yang merupakan sumber bahan baku kalsium fosfat (sintesis mineral tulang) seperti hydroxyapatite, HAp $\left(\mathrm{Ca}_{10}\left(\mathrm{PO}_{4}\right)_{6}(\mathrm{OH})_{2}\right)$ (Ferraz, Monteiro et al. 2004, Malde, Graff et al. 2010) belum dimanfaatkan. Ini terlihat dari peneliti terdahulu seperti penggunaan serbuk tulang ayam sebagai penurun intensitas warna air gambut (Darmayanto 2009). Pembuatan gelatin dari tulang ayam boiler dengan proses hidrolisa (Retno 2012). Sedangkan Harris et al. (2012) melakukan penelitian tentang potensi pengembangan industri tepung ikan dari limbah pengolahan makanan tradisional khas Palembang berbasis ikan (Harris, Efreza et al. 2012). Winarsih et al (2012) di tahun yang sama menentukan pengaruh perendaman limbah tulang ayam menggunakan $\mathrm{NaOH}$ terhadap tingkat dekolagenasi, kandungan Kalsium dan Fospor (Winarsih, Rusmana et al. 2012). Cucikodana et al. (2012) melakukan penelitian tentang pengaruh perbedaan suhu perebusan dan konsentrasi $\mathrm{NaOH}$ terhadap kualitas serbuk tulang ikan gabus (Channa Striata) (Cucikodana, 
Supriadi et al. 2012). Selanjutnya Mayasaroh et al. (2012) pada tahun yang sama melakukan dekolagenasi, kandungan Kalsium dan Fosfor limbah tulang ayam oleh larutan $\mathrm{KOH}$ (Mayasaroh, Rusmana et al. 2012). Nurlaela et al. (2014) melakukan penelitian tentang pemanfaatan limbah cangkang telur ayam dan bebek sebagai sumber kalsium untuk sintesis mineral tulang (Nurlaela, Dewi et al. 2014). Maftuhin et al. (2014) ditahun yang sama melakukan kajian potensi pemanfaatan tulang ayam sebagai adsorben kation timbal dalam larutan (Maftuhin, Hanifah et al. 2014). Sedangkan Sumarto dan Pareng Rengi (2014) melakukan pengembangan penerapan produksi bersih hasil pengolahan perikanan berbasis ikan patin (Sumarto and Rengi 2014).

Dengan adanya kebutuhan yang terus tumbuh untuk mengganti atau memperbaiki fungsi dari setiap sistem utama dari tubuh (yang rusak) membuat mineral ini diminati untuk dijadikan biomaterial pada aplikasi medis. Ide ini timbul akibat menjamurnya PKL ilegal di Kota Pekanbaru, seiring dengan terus bertambahnya limbah tulang ayam dan ikan dari PKL tersebut. Dengan mengembangkan produk bersih, tidak beracun dan ramah lingkungan menjadi fokus penelitian ini. Panelitian ini juga memberikan informasi seberapa besar peningkatan nilai ekonomis dan potensi limbah tulang ayam dan ikan dari PKL di Kota Pekanbaru untuk dijadikan sumber bahan baku kalsium fosfat (sintesis mineral tulang) seperti hydroxyapatite, HAp $\left(\mathrm{Ca}_{10}\left(\mathrm{PO}_{4}\right)_{6}(\mathrm{OH})_{2}\right)$ (Ferraz, Monteiro et al. 2004, Malde, Graff et al. 2010) dan tricalcium phosphate (TCP).

\section{METODOLOGI PENELITIAN}

Penelitian pemanfaatan limbah tulang ayam dan ikan dari PKL sebagai sumber mineral potensial untuk kalsium fosfat dilakukan dalam beberapa tahap. Tahap pertama diawali dengan survei pendahuluan, pengumpulan data, pengolahan data dan percobaan pembuatan serbuak tulang seperti yang ditampilkan pada gambar 1. Survei awal dilakukan untuk mengetahui gambaran menyeluruh tentang PKL yang ada di Kota Pekanbaru. Data yang terkumpul terbagi menjadi dua, yaitu: data primer dan data skunder. Data primer merupakan data hasil pengamatan langsung di lapangan (observasi), wawancara dengan pedagang kaki lima dan pengisian kuisioner. Sedangkan data skunder yang digunakan pada penelitian ini adalah data yang berasal dari Dinas Pasar Kota Pekanbaru, data statistik dan hasil penelitian sebelumnya.

Usaha untuk menentukan potensi bahan baku dari limbah tulang dilakukan dengan mengambil limbah tulang ayam dan ikan langsung dari PKL. Langkah selanjutnya adalah mencuci limbah tulang dengan air sulingan dan dilanjutkan dengan mencuci tulang tersebut menggunakan $\mathrm{NaOH}$ di dalam ultrasonic cleaner pada temperatur $40{ }^{\circ} \mathrm{C}$ selama 1 jam. Setelah bersih tulang tersebut dikeringkan di dalam oven pada temperatur $100{ }^{\circ} \mathrm{C}$ selama 15 menit. Setelah kering, dilakukan proses penimbangan untuk mendapatkan randemen dari tulang (perbandingan antara berat ayam dan ikan dalam kondisi utuh dengan berat tulang yang sudah kering). Proses selanjutnya adalah proses pembakaran atau yang dikenal dengan proses kalsinasi. Proses ini dilakukan di dalam tungku pada temperatur $700{ }^{\circ} \mathrm{C}$ selama 6 jam. Setelah tulang dingin dilakukan proses penggilingan untuk dijadikan serbuk tulang. Setelah menjadi serbuk tulang dilakukan penimbangan kembali, guna mendapatkan randemen yang merupakan perbandingan antara tulang kering dengan serbuk tulang ayam dan ikan.

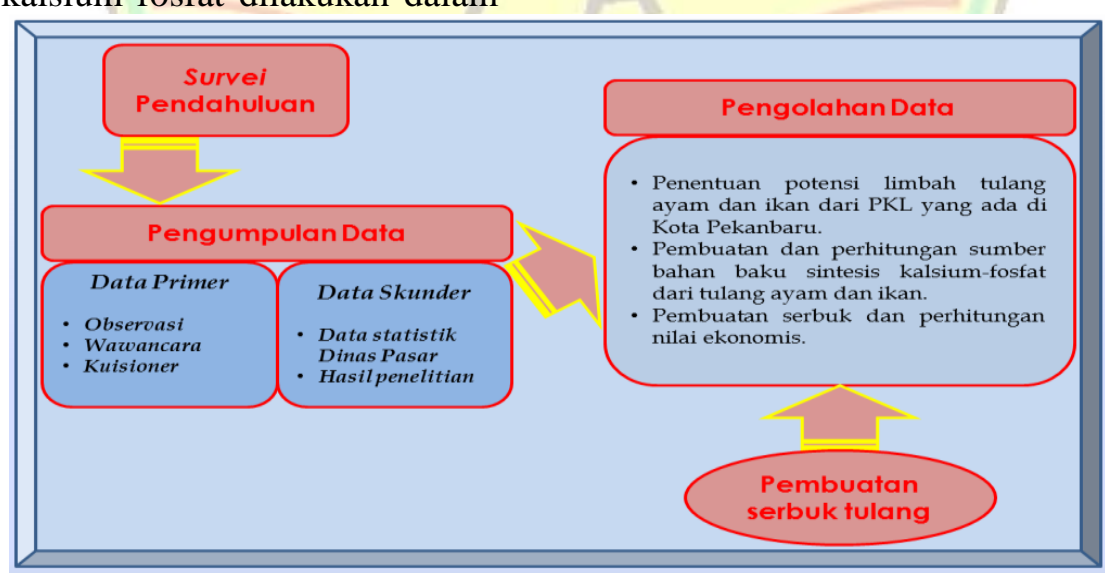

Gambar 1. Diagram alir penelitian 


\section{HASIL DAN PEMBAHASAN}

Penentuan potensi bahan baku tulang ayam dan ikan dihitung berdasarkan jumlah PKL yang berjualan berdasarkan jenis makanan seperti ayam bakar, ayam penyet dan pecel lele. Berdasarkan data hasil survei yang dibandingkan dengan data Dinas Pasar Kota Pekanbaru diperoleh jumlah PKL yang berjualan dengan jenis makanan di atas adalah sebanyak $10 \%$ dari jumlah PKL ilegal (278 PKL). Data survei menunjukkan bahwa konsumsi rata-rata ayam dan ikan setiap PKL sebanyak $12 \mathrm{~kg} /$ malam dan $10 \mathrm{~kg} / \mathrm{malam}$. Hasil pengamatan dilapangan menunjukkan bahwa $1 \mathrm{~kg}$ ayam utuh dapat menghasilkan 73 gram tulang ayam bila proses memasak dengan bakar. Sedangkan 51 gram untuk ayam yang dimasak dengan proses goreng. Dari kedua proses pengolahan ayam (proses dibakar dan digoreng) diambil rataratanya, yakni 62 gram. Artinya randemen dari limbah tulang ayam dari PKL adalah $6.2 \%$ dari berat ayam 1000 gram. Sedangkan untuk $1 \mathrm{~kg}$ ikan hanya menghasilkan tulang ikan sebesar 14 gram (dimasak dengan proses goreng) atau randemen dari tulang ikan adalah sebesar $1.4 \%$.

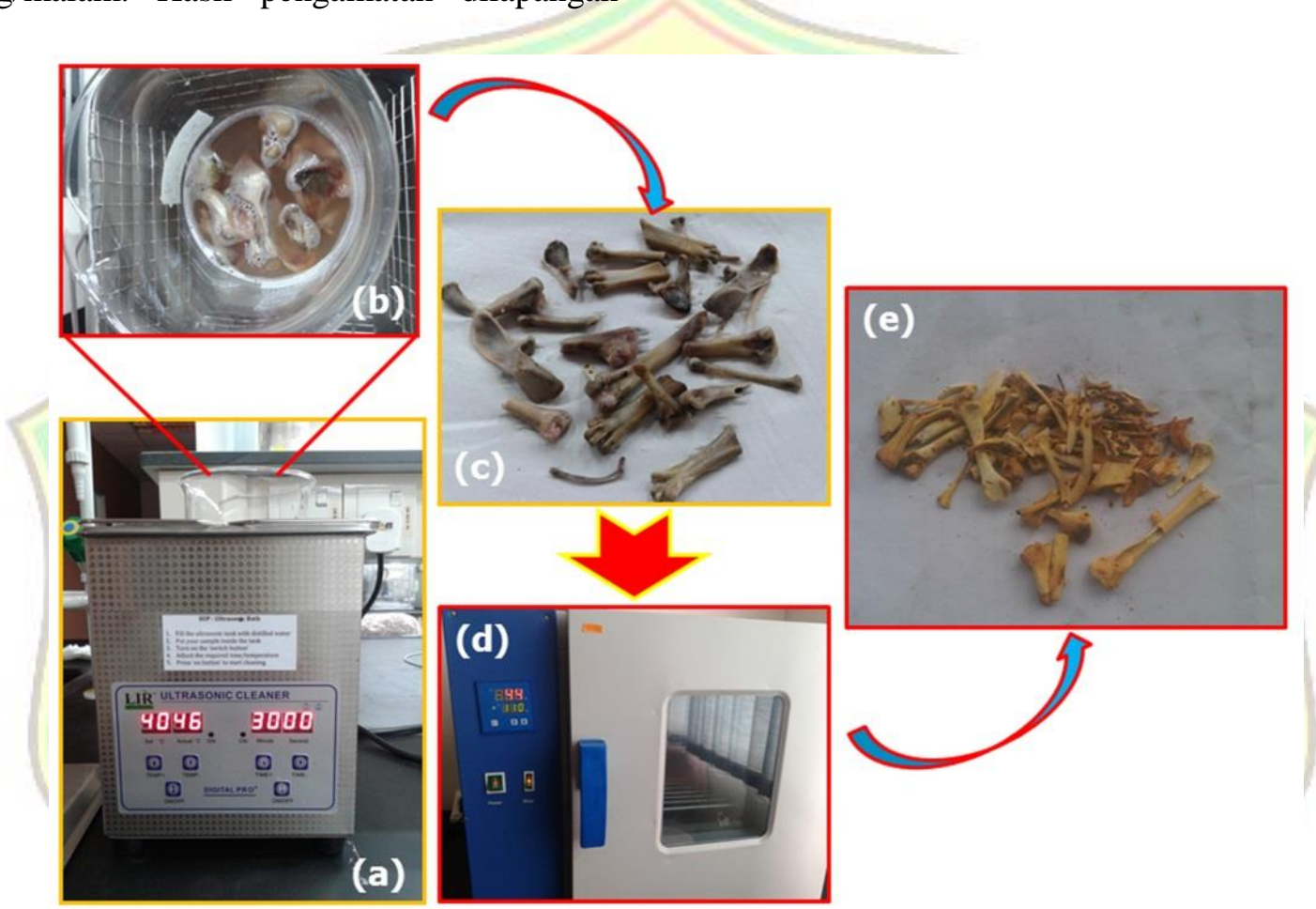

Gambar 2. (a) \& (b) pencucian tulang dengan $\mathrm{NaOH}$ dalam ultrasonic cleaner (c) tulang yang sudah bersih (d) proses pengeringan tulang dengan oven pada $100{ }^{\circ} \mathrm{C}(\mathrm{e})$ tulang yang sudah kering.

Untuk menghitung potensi tulang ayam dan ikan dari PKL di Kota Pekanbaru dapat mengalikan hasil perhitungan (1) dan (2) dengan jumlah PKL yang berjualan berdasarkan jenis makanan seperti ayam bakar, ayam penyet dan pecel lele yakni sebanyak 278 PKL.

Potensi tulang ayam per PKL per malam sebesar:

$12 \mathrm{~kg} / \mathrm{malam} X 62 \mathrm{gram} / \mathrm{kg}$ berat ayam $=744 \mathrm{gram} / \mathrm{PKL} / \mathrm{malam}$.

Potensi tulang ikan per PKL per malam sebesar: $10 \mathrm{~kg} / \mathrm{malam}$ X 14 gram $/ \mathrm{kg}$ berat ikan $=140$ gram $/ \mathrm{PKL} / \mathrm{malam}$.

Jadi, potensi tulang ayam dari PKL di Kota Pekanbaru sebesar:

744 (gram/malam/PKL) X 278 PKL

$$
\begin{aligned}
& =206,832 \mathrm{gram} / \mathrm{malam} \\
& =206.8 \mathrm{~kg} / \mathrm{malam}
\end{aligned}
$$

untuk tulang ikan dari PKL di Kota Pekanbaru sebesar:

$$
\begin{aligned}
& 140(\mathrm{gram} / \mathrm{malam} / \mathrm{PKL}) \text { X } 278 \mathrm{PKL} \\
& =38,920 \text { gram } / \text { malam } \\
& =39 \mathrm{~kg} / \mathrm{malam}
\end{aligned}
$$

Perhitungan jumlah serbuk tulang ditentukan berdasarkan eksperimen murni dari proses pengeringan dan pembakaran tulang (kalsinasi) seperti terlihat pada gambar 3. Hasil pembakaran tulang ayam yang berhasil dijadikan serbuk sebesar 8.4 gram. Sedangkan pembakaran tulang ikan yang berhasil menjadi serbuk tulang ikan sebesar 3.1 gram. 


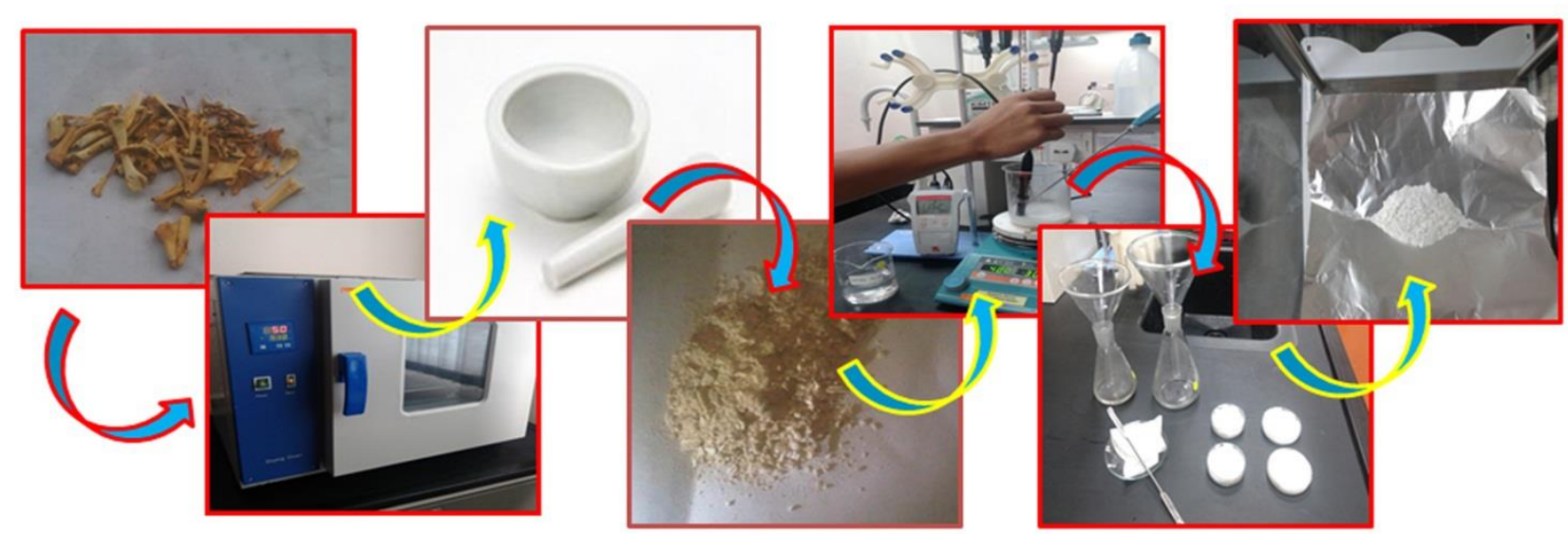

Gambar 3. Proses pembuatan serbuk tulang sampai serbuk tulang berukuran nanopartikel

Randemen serbuk tulang ayam untuk serbuk tulang ayam didapat sebesar 8.4 gram / 62 gram)X $100 \%=13.5 \%$. Sedangkan untuk tulang ikan randemen yang diperoleh sebesar (3.1 gram $/ 14$ gram) $\mathrm{X} 100 \%=22.1 \%$.

Sehingga, potensi serbuk tulang ayam per PKL per malam di Kota Pekanbaru sebesar:

$12 \mathrm{~kg} / \mathrm{malam} X 8.4 \mathrm{gram} / \mathrm{kg}$ berat ayam

$=100.8 \mathrm{gram} / \mathrm{PKL} / \mathrm{malam}$.

potensi serbuk tulang ikan per PKL per malam di Kota Pekanbaru sebesar:

$10 \mathrm{~kg} / \mathrm{malam} X 3.1 \mathrm{gram} / \mathrm{kg}$ berat ikan

$=31 \mathrm{gram} / \mathrm{PKL} / \mathrm{malam}$.

Jadi,

potensi serbuk tulang ayam dari PKL di Kota Pekanbaru sebesar:

100.8 (gram/malam/PKL) X 278 PKL

$=28,022.4 \mathrm{gram} / \mathrm{malam}$

$=28 \mathrm{~kg} / \mathrm{malam}$

untuk tulang ikan dari PKL di Kota Pekanbaru sebesar:

31 (gram/malam/PKL) X $278 \mathrm{PKL}$

$=8,618 \mathrm{gram} / \mathrm{malam}$

$=8.6 \mathrm{~kg} / \mathrm{malam}$

Peningkatan nilai ekonomis berdasarkan potensi serbuk tulang ayam dan ikan dari limbah PKL di Kota Pekanbaru sebesar 28 kg/malam + $8.6 \mathrm{~kg} / \mathrm{malam}=36.6 \mathrm{~kg} / \mathrm{malam}$. Untuk harga jual serbuk tulang bergantung kepada kadar protein mulai dari $20 \%$ sampai dengan $60 \%$
(ROBBANY 2015). Untuk harga per kg serbuk tulang juga bervariasi mulai dari Rp. 3,500/kg sampai Rp. 12,000/kg (ROBBANY 2015). Jika diasumsikan produk serbuk tulang yang diproduksi dengan kualitas menengah maka untuk harga/kg dari serbuk tulang adalah Rp. 6,000/kg (ROBBANY 2015). Sehingga peningkatan nilai ekonomis dari limbah tulang ayam dan ikan sebesar: $36.6 \mathrm{~kg} / \mathrm{malam} \mathrm{X} \mathrm{Rp}$. $6,000 / \mathrm{kg}=$ Rp. 219,600,-/malam. Jika dijadikan serbuk tulang dalam ukuran nanopartikel, maka harga jualnya 49,410,000,-/malam (Kurs 1 US \$ $=$ Rp. 13,500,-)

\section{KESIMPULAN}

- Potensi limbah tulang ayam dan ikan dari PKL yang ada di Kota Pekanbaru masingmasing sebesar $206.8 \mathrm{~kg} / \mathrm{malam}$ dan 39 $\mathrm{kg} / \mathrm{malam}$.

- Potensi sumber bahan baku sintesis kalsium dari tulang ayam dan ikan masing-masing sebesar $28 \mathrm{~kg} / \mathrm{malam}$ dan $8.6 \mathrm{~kg} / \mathrm{malam}$.

- Peningkatan nilai ekonomis jika memproduksi serbuk tulang Rp. 219,600,/malam

- Peningkatan nilai ekonomis jika memproduksi serbuk tulang dengan ukuran nanopartikel Rp. 49,410,000,-/malam

\section{DAFTAR PUSTAKA}

Balázsi, C., et al. (2007). "Examination of Calcium-Phosphates Prepared from Eggshell." Materials Science Forum 537-538: 105-112. 
Balázsi, C., et al. (2007). "Preparation of calcium-phosphate bioceramics from natural resources." Journal of the European Ceramic Society 27(2-3): 1601-1606.

Cucikodana, Y., et al. (2012). "Pengaruh Perbedaan Suhu Perebusan Dan Konsentrasi $\mathrm{NaOH}$ Terhadap Kualitas Bubuk Tulang Ikan Gabus (Channa Striata)." Jurnal Fishtech 1(1): 91-101.

Darmayanto (2009). Penggunaan Serbuk Tulang Ayam Sebagai Penurun Intensitas Warna Air Gambut. Program Studi Ilmu Kimia. Medan, Universitas Sumatera Utara.

de Groot, K. (1980). "Bioceramics consisting of calcium phosphate salts." Biomaterials 1(1): 47-50.

Ferraz, M. P., et al. (2004). "Hydroxyapatite nanoparticles: A review of preparation methodologies." Journal of Applied Biomaterials \& Biomechanics 2(2): 7480.

Gergely, G., et al. (2010). "Preparation and characterization of hydroxyapatite from eggshell." Ceramics International 36(2): 803-806.

Harris, H., et al. (2012). "Potensi Pengembangan Industri Tepung Ikan Dari Limbah Pengolahan Makanan Tradisional Khas Palembang Berbasis Ikan." Jurnal Pembangunan Manusia 6(3): 1-15.

Jang, H. and S.-H. Kang (2002). "Phosphorus removal using cow bone in hydroxyapatite crystallization." Water Research 36(5): 1324-1330.

Lee, S. J. and S. H. Oh (2003). "Fabrication of calcium phosphate bioceramics by using eggshell and phosphoric acid." Materials Letters 57(29): 4570-4574.

Maftuhin, et al. (2014). Potensi Pemanfaatan Tulang Ayam Sebagai Adsorben Kation Timbal Dalam larutan. Pekanbaru, Fakultas Matematika dan Ilmu Pengetahuan Alam, Universitas Riau: 18.

Malde, M. K., et al. (2010). "Fish bones - a highly available calcium source for growing pigs." Journal of Animal Physiology and Animal Nutrition 94(5): e66-e76.

Mayasaroh, I., et al. (2012). Dekolagenasi, Kandungan Kalsium dan Fosfor Limbah Tulang Ayam oleh Larutan KOH. Bandung, Fakultas Peternakan Universitas Padjadjaran.

Nikpour, M. R., et al. (2012). "Synthesis and characterization of hydroxyapatite/chitosan nanocomposite materials for medical engineering applications." Composites Part B: Engineering 43(4): 1881-1886.

Nurlaela, A., et al. (2014). "Pemanfaatan Limbah Cangkang Telur Ayam dan Bebek sebagai Sumber Kalsium untuk Sintesis Mineral Tulang." Jurnal Pendidikan Fisika Indonesia 10(1): 8185.

Ozawa, M. and S. Suzuki (2002). "Microstructural Development of Natural Hydroxyapatite Originated from Fish-Bone Waste through Heat Treatment." Journal of the American Ceramic Society 85: 1315-1317.

Retno, D. T. (2012). Pembuatan Gelatin Dari Tulang Ayam Boiler Dengan Proses Hidrolisa. Seminar Nasional Aplikasi Sains \& Teknologi (SNAST) Periode III, Yogyakarta.

Ripamonti, U., et al. (2009). "The induction of bone formation by coral-derived calcium carbonate/hydroxyapatite constructs." Biomaterials 30(7): 14281439.

Rivera, E. M., et al. (1999). "Synthesis of hydroxyapatite from eggshells." Materials Letters 41(3): 128-134.

ROBBANY, C. B. A. (2015). "TEPUNG TULANG IKAN KUALITAS TINGGI UNTUK PAKAN TERNAK." Retrieved 11 Desember, 2015, from http://agrobisnisprobolinggo.blogspot.co .id/2013/12/tepung-tulang-ikan-kualitastinggi-dan.html.

Saiz, E., et al. (2007). "Preparation of porous hydroxyapatite scaffolds." Materials 
Science and Engineering: C 27(3): 546550.

Sumarto and P. Rengi (2014). Pengembangan

Penerapan Produksi Bersih Hasil Pengolahan Perikanan Berbasis Ikan Patin. Pekanbaru, Pusat Penelitian Lingkungan Hidup, Universitas Riau.

Vecchio, K. S., et al. (2007). "Conversion of bulk seashells to biocompatible hydroxyapatite for bone implants." Acta Biomaterialia 3(6): 910-918.

Winarsih, W., et al. (2012). "Pengaruh
Perendaman Limbah Tulang Ayam menggunakan $\mathrm{NaOH}$ terhadap Tingkat Dekolagenasi, Kandungan Kalsium dan Fosfor." Students e-Journal Fakultas Peternakan Universitas Padjadjaran 1(1): 1-14.

$\mathrm{Wu}$, S.-C., et al. (2013). "A hydrothermal synthesis of eggshell and fruit waste extract to produce nanosized hydroxyapatite." Ceramics International 39(7): 8183-8188.

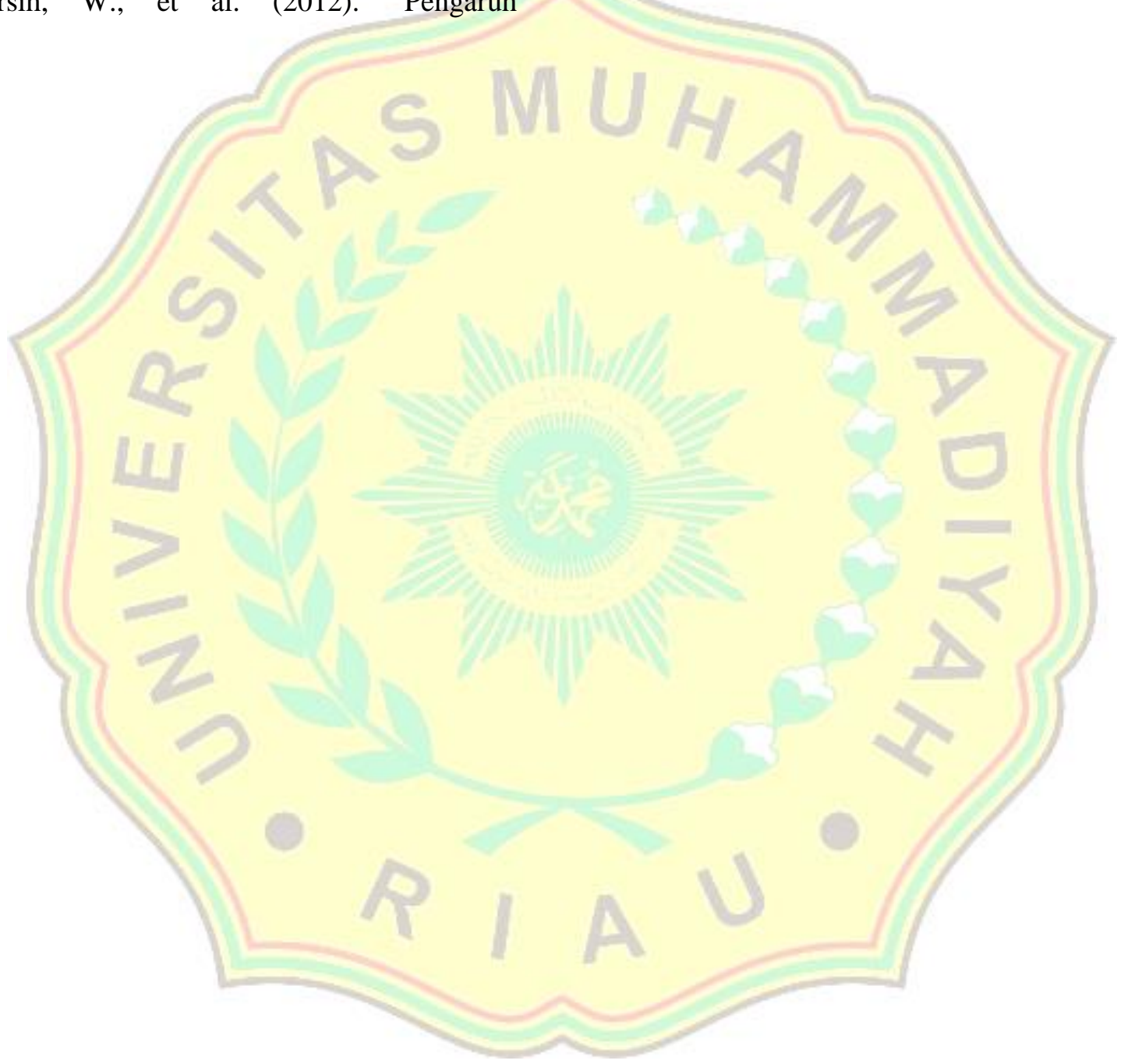

